\title{
Tools for examining subglacial bed deformation
}

\author{
Erik Blake, Garry K. C. Clarke and Marc C. Gérin \\ Department of Geophysics and Astronomy, University of British Columbia, \\ Vancouver, British Columbia V6T 124, Canada
}

\begin{abstract}
Deformation beneath soft-bedded glaciers may be a physical mechanism that contributes to flow instabilities such as surging. If the role of bed deformation is to be understood, a rheological description is required, but the development of a rheology is hampered by a lack of in situ stress and strain measurements. In this paper, we describe four techniques for measuring subglacial strain. Three of these give continuous strain measurements, a capability that permits calculation of instantaneous strain rates and allows comparison of strain data with other time series. To demonstrate the practicability of the techniques, sample results from three summers of experimentation beneath Trapridge Glacier, Yukon Territory, are presented. The data show that subglacial strain rate can vary in amplitude and polarity on an hourly time-scale, and that the instantaneous strain rate can exceed the mean strain rate by an order of magnitude. Observed negative strain rates suggest extrusive flow within basal sediments.
\end{abstract}

\section{INTRODUGTION}

Efforts to describe the mechanics and hydrology of deforming sediment beneath glaciers, ice streams and ice sheets are beset by uncertainties. One of these is the rheological description of deforming water-saturated sediment. At present, the only deformation equations based on in situ measurements are those of Boulton and Hindmarsh (1987), but their data were taken from tunnels in thin ice near the terminus of Breidamerkurjökull, Iceland. It is desirable to complement such measurements with others taken under more representative conditions. This paper introduces four new in situ methods for determining subglacial strain rate and describes a technique for inserting sensors into subglacial material.

We limit the scope of this paper to a description of experimental techniques and include data only to illustrate strengths and weaknesses of each approach, and to draw obvious qualitative conclusions concerning sediment rheology. Approximately $20 \%$ of the beddeformation data we have collected are presented. A full paper describing rheological implications is in preparation.

\section{TECHNIQUE FOR SENSOR INSERTION}

A hollow percussion hammer allows a flexible instrument to be inserted into the stiff glacier bed (Fig. 1). The hammer consists of a $2 \mathrm{~m}$ long tubular stainless-steel body having an inside diameter of $10.87 \mathrm{~mm}$ and an outside diameter of $17.3 \mathrm{~mm}$ [0.375 in, schedule 80 seamless pipe]. Brass blocks of $3.81 \mathrm{~cm}$ [1.500 in] diameter are fixed to both ends of the body. The lower block serves as an anvil for a tubular striker that slides over the body. This striker, which is $60 \mathrm{~cm}$ long and weighs $2.1 \mathrm{~kg}$ in water, is suspended by a $1.59 \mathrm{~mm}$ [0.0625 in] stainlesssteel wire yoke that threads through the upper stop block. The lower-body thread extends below the anvil and allows various accessories to be attached. When installing a bed-strain instrument, we attach an insertion sheath of sufficient internal diameter to allow a loose fit for the instrument. Each instrument is terminated with a conical brass tip that fits snugly into the sheath when the instrument and its cable are threaded through the percussion hammer. The tip has a larger diameter than the sheath, so that the lip of the cone forms a blunt annular barb.

While the hammer, with the bed-strain instrument loaded inside, is lowered down a hole, its weight is carried by the wire rope. The instrument cable is held just tight enough to keep the instrument from sliding out of the hammer. To avoid jostling the assembly, the rope and cable are laid out on the ice surface and the operator walks toward the hole from a distance greater than the thickness of the glacier, holding both lines. When bottom is reached, the taut instrument cable is marked level with the ice surface. As the wire rope is used to drop the striker repeatedly against the anvil, percussive forces are transferred to the brass tip; the instrument remains protected within the sheath. The cable is left slack during hammering to avoid placing tension on the instrument. Insertion depth is measured by observing the displacement of the mark with respect to the ice surface, although this displacement does not reflect the position of the instrument with respect to the ice-bed interface. Hydraulic excavation by our hot-water drill 


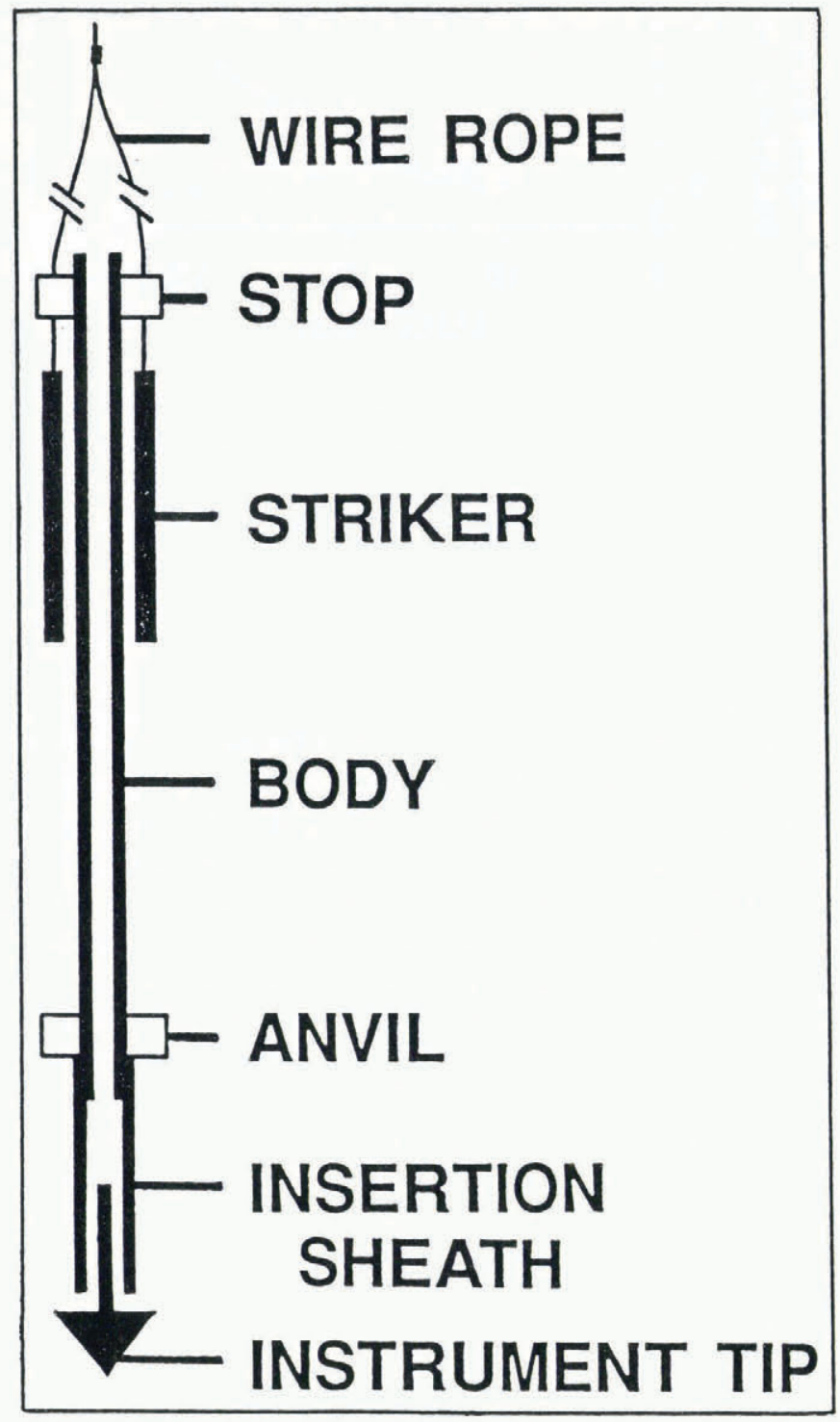

Fig. 1. Schematic diagram (not to scale) of the borehole percussion hammer used to inserl flexible strain instruments into the soft bed of Trapridge Glacier. The tool is sufficiently narrow that a figure drawn to scale would hide details.

creates a soft, decimeters-thick disturbed layer in the subglacial material through which the hammer penetrates by virtue of its static weight. The hammering procedure results in penetration of the underlying undisturbed basal material. Thus, even if the length of the instrument is less than the insertion depth into undisturbed material, the entire instrument may be below the ice bed interface.

As many as one hundred blows may be required before the hammer ceases to advance. When the hammer is withdrawn, the lip of the instrument tip catches in the sediment and withdraws the instrument from the sheath. Once the hammer has been lifted to the surface, the instrument cable is tied off at the surface with $1-1.5 \mathrm{~m}$ of slack cable let down the hole.

\section{QUALITATIVE MEASUREMENTS}

Bed-strain measurements were first attempted during the
1987 field season. Our primary goal was to determine whether measurements of bed deformation were possible using the percussion-hammer insertion technique. With this in mind, we developed two simple methods for making qualitative strain measurements: the bed cast and the rubber rod.

\section{Bed casting}

The bed cast is a simple method for measuring total strain. A length of vinyl tubing, containing freshly mixed casting resin and a heating wire, is hammered into the bed. At freezing temperatures, the catalyzing reaction is effectively halted, so the tube remains flexible. After several days of deformation, the resin is heated and hardened by passing a current through the wire. The stiff

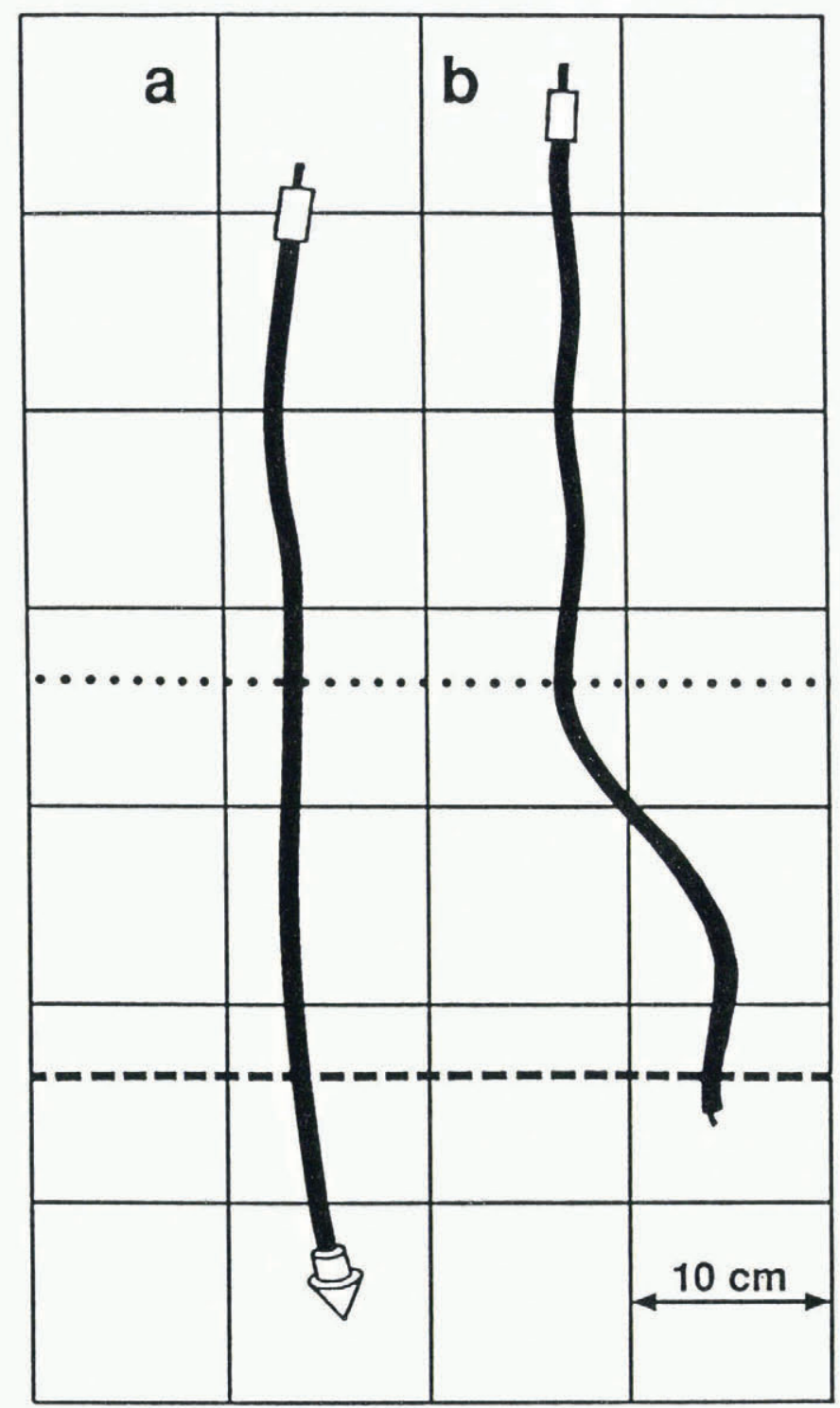

Fig. 2. Tracings, from pholographs, of Trapridge Glacier bed casts on a $10 \mathrm{~cm}$ by $10 \mathrm{~cm}$ grid. (a) $A$ bed cast catalyzed and withdrawn immediately after insertion. (b) $A$ bed cast left in the deforming layer for $92 \mathrm{~h}$ before removal (the tip was lost upon withdrawal). The dashed line indicates the upper boundary of the undisturbed bed into which the bed casts were hammered; the dotted line indicates the estimated location of the ice-bed interface. 
tube, now a cast of the deformation to which it has been subjected, is then pulled out. In most cases, the cast retains enough elasticity to survive passage through the borehole undamaged; if the cast should crack, its shape is easily reconstructed.

In our experiments, we use vinyl tubing having an outside diameter of $6.35 \mathrm{~mm}$ [0.250 in] and an inside diameter of $4.76 \mathrm{~mm}$ [0.1875 in]. The polyester casting resin is doped with the recommended amount of catalyst for hardening at room temperature. The nichrome heating wire has a resistance of $35 \Omega \mathrm{m}^{-1}$. Hardening is accomplished by circulating $0.9-1.3 \mathrm{~A}$ of current through the wire for $\sim 3 \mathrm{~h}$. This represents a power dissipation of $28-59 \mathrm{~W} \mathrm{~m}^{-1}$ into the resin. The nichrome wire is sheathed in teflon "spaghetti" tubing to prevent the vinyl tube from melting. Because the resin is attacked by water, care must be taken to ensure that the instrument is watertight.

Figure 2a shows a cast which was hammered $12 \mathrm{~cm}$ into the bed and then catalyzed immediately. As expected, no deformation is evident. The slight curling of the cast was caused by shrinkage of the resin as it set. Figure $2 \mathrm{~b}$ shows a cast which was inserted $7 \mathrm{~cm}$ into the undisturbed bed, and left $92 \mathrm{~h}$ before heating began. The dashed line in the figure represents the surface of the undisturbed bed material, and the dotted line indicates the estimated location of the ice-bed interface $(20 \mathrm{~cm}$ above the undisturbed material). The distinct doublebend offset near the bottom of the cast suggests that the zone containing the bend was deforming but, because the cast may have extended up into the ice, the bending could be attributed to glacier sliding. During the experiment, the glacier surface above the instrument moved approximately $40 \mathrm{~cm}$.

Two other bed casts were successfully installed in 1987 (a fifth cast was not properly anchored in the bed and detached when the hammer was withdrawn). One, installed to a depth of $12 \mathrm{~cm}$, had a break in its heating circuit and could not be catalyzed. The other, installed to a depth of $35 \mathrm{~cm}$, was held so tightly by the glacier bed that it snapped in two and only the upper $10 \mathrm{~cm}$ of the cast was recovered.

\section{Rubber rod}

To ascertain whether strain rate varies with time, we built a rudimentary strain gauge capable of making continuous qualitative strain measurements. The rubber rod consists of a $20 \mathrm{~cm}$ length of $6.35 \mathrm{~mm}$ [0.250 in] square-section rubber on to which a strain-gauge network is bonded. The rod is sheathed in a glycerin-filled protective vinyl tube. Gauges are bonded on to the faces of the rod near its midpoint and can record flexure along two axes.

Results from $2 \mathrm{~d}$ of observation using this instrument confirmed that temporal changes in the strain rate occur (Fig. 3). The experiment ended when excessive strain caused breaks in the strain-bridge wiring. The glaciersurface velocity was approximately $12 \mathrm{~cm} \mathrm{~d}^{-1}$ during the course of the experiment. The axes of strain are labelled down-flow and cross-flow, assuming that the upwardtrending record (solid line) represents strain in the direction of ice flow, and the second record (dotted line) represents strain perpendicular to this direction. We

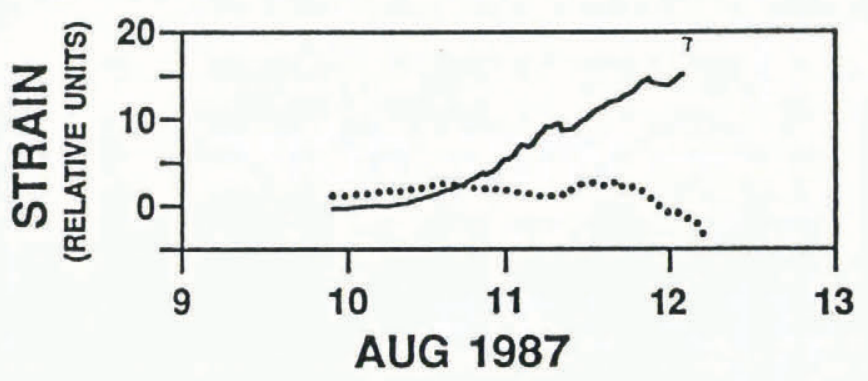

Fig. 3. Results from the 1987 rubber-rod experiment. The vertical scale is in relative strain units, as the device was uncalibrated. The solid line represents strain in the direction of ice flow. The dotted line represents crossflow strain.

believe these assumptions are correct because the physical characteristics of the rod cause it to twist within the vinyl tube so that the bending strain is shifted to one pair of faces. A striking feature of the down-flow strain record is that it is not monotonically increasing. The slope of the curve, which is proportional to strain rate, is occasionally zero or negative. Because deformation counter to the direction of ice flow is unlikely, the negative strain rates suggest sporadic extrusive flow within the deforming layer. Extrusive flow within the layer is not excluded because, unlike the glacier itself, the layer is confined from above and below by rigid boundaries. The glacier forms a rigid upper boundary and non-deforming sediment or bedrock a lower boundary.

\section{QUANTITATIVE MEASUREMENTS}

Our success with qualitative techniques led us to design two types of tilt sensor capable of making continuous quantitative measurements of strain rate at several levels within the bed. Tilt sensors can be used to compute instantaneous strain rates (averaged over the length of the cell) by numerical differentiation of the tilt time series. The method treats the sensor as a clast experiencing rigidbody rotation as a result of being placed in a straining medium. The inhomogeneous nature of the basal material introduces complications relating to the scale of observation, but we can provide a framework for the interpretation of strain data. The question of scale of observation is addressed below.

Consider a coordinate system having its $x$ axis positive in the direction of ice flow, and the $z$ axis normal to the bed and positive upward. In a macroscopically homogeneous material, the strain rates $\dot{\epsilon}_{x z}$ and $\dot{\epsilon}_{y z}$ are defined as

$$
\dot{\epsilon}_{x z}=\frac{1}{2}\left(\frac{\partial u}{\partial z}+\frac{\partial w}{\partial x}\right)
$$

and

$$
\dot{\epsilon}_{y z}=\frac{1}{2}\left(\frac{\partial v}{\partial z}+\frac{\partial w}{\partial y}\right)
$$

where $u, v$ and $w$ are the down-flow, cross-flow and upward components of velocity, respectively. If $\partial w / \partial x$ 
and $\partial w / \partial y$ are negligible, these equations become

$$
\dot{\epsilon}_{x z}=\frac{1}{2} \frac{\partial u}{\partial z}=\frac{1}{2} \frac{\partial \tan \theta_{\mathrm{d}}}{\partial t}
$$

and

$$
\dot{\epsilon}_{y z}=\frac{1}{2} \frac{\partial v}{\partial z}=\frac{1}{2} \frac{\partial \tan \theta_{c}}{\partial t}
$$

where the velocity gradients are expressed as the rate of change of down-flow tilt angle $\theta_{\mathrm{d}}$ and cross-flow tilt angle $\theta_{\mathrm{c}}$. Tilt angle is measured with respect to the $z$ axis; positive tilt corresponds to tilt in the positive $x$ and $y$ directions.

\section{Electrolytic tilt sensors}

Electrolytic tilt cells operate on the principle that the conductance between two electrodes immersed in an electrolyte is proportional to the total wetted surface area of the electrodes. A single-axis electrolytic tilt cell consists of three electrodes partially immersed in an electrolyte (Fig. 4). Electrodes may descend from the top of the cell or ascend from the bottom. As the cell is rotated about the plane of the electrodes, the central electrode remains immersed to the same level and the lateral electrodes are dipped in and out of the electrolyte. To make a tilt measurement, the tilt cell is connected to an a.c. bridge containing two reference resistors (a.c. excitation prevents electrode polarization). The magnitude of the output voltage of the cell is roughly proportional to the tangent of the tilt angle, and the sign determines the tilt direction. A dual-axis tilt cell has five electrodes arranged in a "+" pattern with the central electrode common to both circuits.

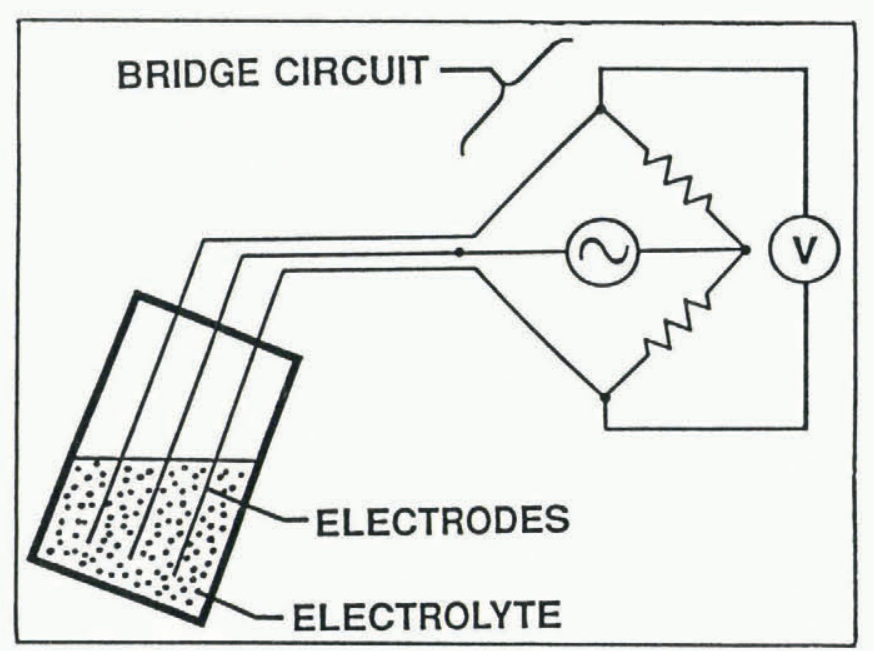

Fig. 4. Schematic diagram of the electrolytic tilt cell and electronics used in the 1988 experiment. The cell is $57 \mathrm{~mm}$ long and $16 \mathrm{~mm}$ in diameter. An a.c. excited bridge is formed between the cell and two reference resistors. As the cell is tilted, the lateral electrodes dip in and out of the electrolyte and their resistance with respect to the central electrode changes. The bridge imbalance is measured to give the degree and polarity of tilt. For dual axis-tilt sensitivity, a second pair of lateral electrodes is mounted at right-angles to the first pair and the central electrode is shared by both circuits.
Our tilt cells have copper electrodes suspended from the top of an acrylic cell. The electrolyte is a weak solution of Alconox, a common laboratory detergent. The space above the electrolyte is filled with naphtha to prevent water infiltration under pressure. When microfractures are etched in the surface of the acrylic by rinsing it for $5 \mathrm{~s}$ in methanol, no visible meniscus forms between these two fluids. The fluid interface remains horizontal as the cell is tilted. The presence of a meniscus would interfere with accurate measurements of tilt because the electrodes are in close proximity to the wall of the cell.

Our choice of immiscible fluids represents the best formula picked during a series of desperate in-field tests. During the 1988 field season, we discovered that the original electrolyte choice - saturated copper-sulphate solution - did not behave properly in the presence of naphtha or any other insulating fluid available to us. We are certain that better choices exist (such as those in commercial devices) and we do not recommend that this electrolyte formulation be used.

Three cells, each $57 \mathrm{~mm}$ long and $16 \mathrm{~mm}$ in diameter, are assembled into a string at a centre-to-centre spacing of $10 \mathrm{~cm}$. The string is cased in a protective sheath of heatshrink tubing, and the lowermost cell is fitted into the insertion tip. Prior to insertion, the cells are calibrated on a special jig. The jig allows a cell to be rotated about its long axis while the tilt of the axis is fixed at various angles. Our cells are calibrated at tilt angles ranging between $0^{\circ}$ and $60^{\circ}$ from vertical. For each calibration-tilt angle $\theta_{i}$, the output voltages from each tilt circuit are fitted, using least squares, to functions of the form

$$
V\left(\theta_{i}, \phi\right)=A_{i} \sin \left(\phi+B_{i}\right)+C_{i}
$$

where the subscript $i$ enumerates the discrete tilt angles, $A_{i}$ are the fitted signal amplitudes at those tilt angles, $B_{i}$ are the azimuth offsets, $C_{i}$ are voltage offsets, $\phi$ represents the azimuth of the tilt and $V$ is the predicted voltage output. It is important to note that the azimuth $\phi$ is measured in a local coordinate system where the $z$ axis is aligned with the long axis of the tilt cell; the azimuth is in no way equivalent to orientation in a geographical coordinate system.

A tilt cell consists of two tilt circuits, so each cell has two sets of functions of this form associated with it. For a given tilt angle, the circuits in a perfect cell would have values of $B$ differing by exactly $90^{\circ}$. In practice, the electrode groups are imperfect and the values of $B$ differ by roughly $90^{\circ}$. When the field data are analyzed, a natural cubic spline (Press and others, 1986, p. 86) interpolates values of $A, B$ and $C$ at tilt angles intermediate to those for which calibrations were performed. This transforms the two sets of discrete calibration functions for a specific cell into the continuous system of equations

$$
\begin{aligned}
& V_{x}(\theta, \phi)=A_{x}(\theta) \sin \left[\phi+B_{x}(\theta)\right]+C_{x}(\theta) \\
& V_{y}(\theta, \phi)=A_{y}(\theta) \sin \left[\phi+B_{y}(\theta)\right]+C_{y}(\theta)
\end{aligned}
$$

where the subscripts $x$ and $y$ distinguish the orthogonal tilt circuits. The Newton-Raphson method for non-linear systems of equations (Press and others, 1986, p. 269) is used to calculate the values of $\theta$ and $\phi$ that would give the observed output voltages $V_{x}$ and $V_{y}$. The error on tilt and 
azimuth for these sensors was estimated by using the calibration data as input to the inversion scheme. The tilt-angle error is $\pm 1^{\circ}$ at $0^{\circ}$ of tilt, increasing to $\pm 2^{\circ}$ at $30^{\circ}$ of tilt, and to $\pm 3^{\circ}$ at $60^{\circ}$ of tilt. The azimuth error is $\pm 5^{\circ}$. Though these errors are large, they are systematic. We believe that the relative error between successive measurements is negligible because the tilt and azimuth records appear smooth. Based on zero relative error, the error in strain rate is $1 \%$ at $0^{\circ}$ of tilt, increasing to $4 \%$ at $30^{\circ}$ of tilt and to $20 \%$ at $60^{\circ}$ of tilt.

On 10 August 1988, an electrolytic tilt-sensor string was hammered $8 \mathrm{~cm}$ into the undisturbed bed of Trapridge Glacier. Figure 5 shows the results for $23 \mathrm{~d}$ of observation. The data are presented in the raw form generated by applying the calibration functions: the solid lines indicate tilt from vertical and the dotted lines indicate the azimuth of the tilt with respect to the internal coordinates of the cell. During the course of the experiment, the glacier surface in the study area moved about $10 \mathrm{~cm} \mathrm{~d}^{-1}$.

The data for the lowest two tilt cells indicate an initial net tilt angle of about $45^{\circ}$; this is a surprisingly large value. The deformation instrument is inserted co-axially with the bottom of the borehole, but this borehole had a

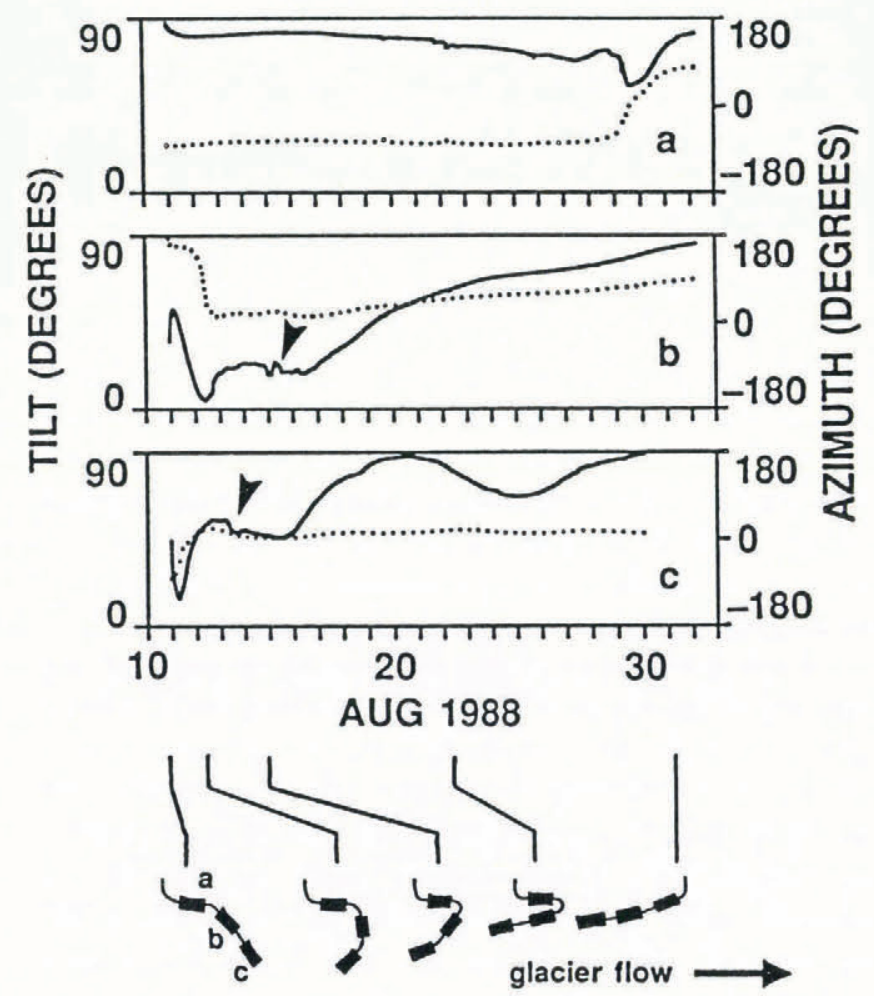

Fig. 5. The $23 d$ record from the 1988 electrolytic tiltsensor string. The upper, middle and lower cells are labelled (a), (b) and (c), respectively. Solid lines indicate tilt from vertical (left scale); dotted lines indicate the azimuth of the tilt with respect to the internal coordinates of the cell (right scale). The records from the two lower cells indicate that they were within a deformation zone that sometimes experienced zero and negative strain rates. The arrows indicate these times. The cartoon below the graphs shows the position of the individual cells within the deforming layer at specific times. Ice movement is to the right. $3^{\circ}$ up-glacier tilt. Some other disturbance caused the tilt cells to "fall over" shortly after the percussion hammer was removed. We believe that the heat-shrink sheath stiffened the instrument sufficiently so that, when slack cable was lowered down the borehole, the instrument was pushed over. Even the bottom cell, which was inserted into undisturbed material, was affected. Evidently, the disturbed layer of the bed was not firm enough to prevent this motion. The rapid onset (within 1d) of independent cell motion suggests that the disturbed layer solidified quickly, allowing further shear deformation to be recorded.

If we assume that the principal direction of tilt is in the down-flow direction, we can further decompose the net tilt and azimuth values into down-flow and cross-flow components of tilt. Variations in the azimuth of a tilt cell result from three motions: (1) rotation of the tilt cell about its long axis, (2) shear-like movement of the tilt cell in a direction perpendicular to the vertical plane passing through its axis (this will also change the net tilt angle) and (3) pivoting of the tilt cell through a near-vertical orientation. This last movement results in a distinctive $180^{\circ}$ shift in azimuth and a sharp dip in the net tilt angle. In the absence of information on the orientation of the tilt cell in a geographical coordinate system, the relative contribution of each of the first two motions to changes in azimuth are unknown. In order to interpret the data, we make the assumption that azimuth changes due to rotation are generally long-term (over several days) and that changes due to shearing are generally short-term (less than $1 \mathrm{~d}$ ). The basis for this assumption lies in the observation that the azimuth time series tends to be a slowly varying function upon which fluctuations are superimposed. By attributing the azimuth drift to cell rotation (which has no effect on strain rates), we can isolate the azimuth fluctuations, which in turn are attributed to both rotation and shear. This assumption is of little consequence because altering the partitioning of azimuth change between these two motions has a surprisingly small effect on the computed strain rates. In our analysis, the azimuth drift is removed by subtracting a linear drift function. The decomposition process must also account for the initial orientation of the tilt cell relative to the glacier-flow direction; the initial cross-flow tilt may be non-zero.

The azimuth records shown in Figure 5 show little variation from piece-wise straight lines and, for this sensor string, the dip direction of the hole is aligned with the glacier-flow direction. We conclude that almost all the tilt for this particular data set is in the down-flow direction, so the data separate naturally into down-flow and crossflow tilts. The component decomposition for these data is not shown because we wish to show the smooth character of the raw data, but the decomposition would show a near-zero cross-flow tilt and a down-flow tilt mimicking the net tilt. Early in the experiment, each of the lower two cells experienced a $180^{\circ}$ shift in azimuth associated with a sharp decrease in tilt angle. This suggests that these two cells originally tilted up-glacier; the azimuth shift indicates when each cell pivoted to tilt down-glacier.

It is evident that all the cells quickly reached an orientation outside their calibrated range. Indeed, the uppermost cell seems to have passed the whole exper- 


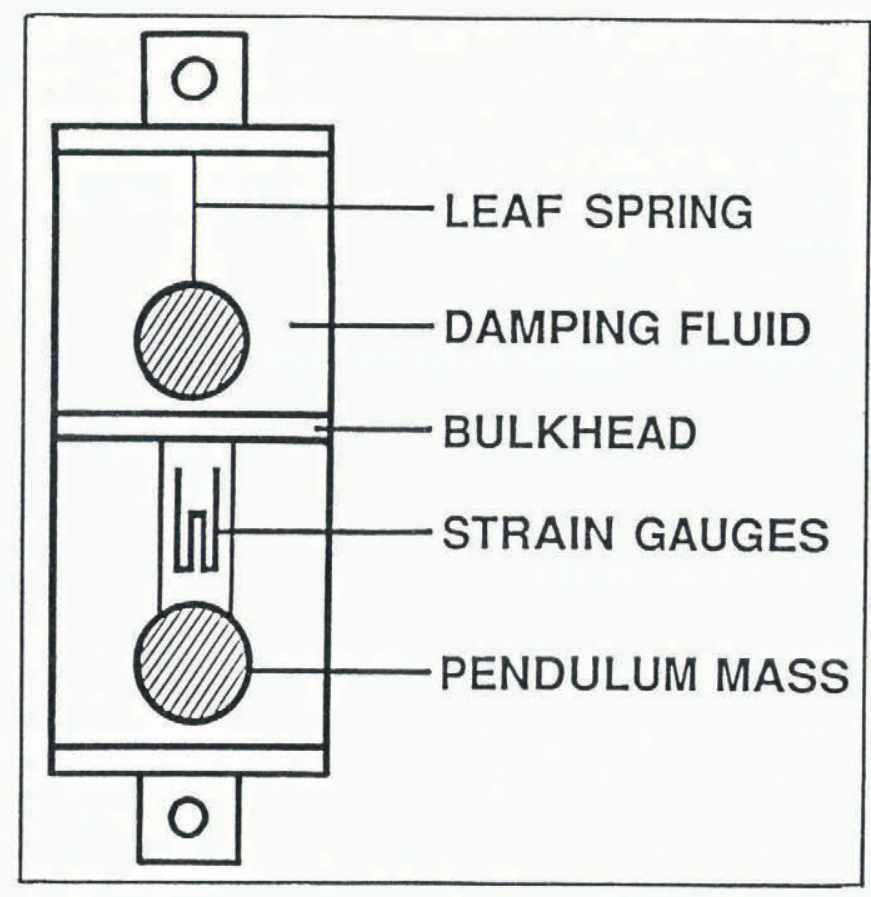

Fig. 6. Schematic diagram of the leaf-spring till cell used in the 1989 experiment. The cell is $47 \mathrm{~mm}$ long and $16 \mathrm{~mm}$ in diameter. As the cell is tilted, the pendulum masses bend the two leaf springs mounted at right-angles to each other. The leaf springs are only sensitive to bending in one direction, so the two pendula respond to till along different axes. The bending is measured by strain gauges bonded to the surfaces of the leaf springs.

iment resting on its side. Late in the experiment, this cell was tipped over, probably by the glacier pulling on the cable. As with the strain record from the rubber rod, brief intervals of zero and negative strain rate are observed. These are indicated by arrows on the figure.

\section{Leaf-spring tilt sensors}

The disadvantages of our electrolytic tilt cell are that it has a limited range over which tilt measurements can be made and that the measurement error is large. Special attention must be paid to sealing the cell and care must be taken in choosing a suitable stable electrolyte. These problems are overcome with the leaf-spring sensor illustrated in Figure 6.

Two leaf-spring pendula measure the tilt along perpendicular axes. Each leaf spring consists of a small clamped strip of $50.8 \mu \mathrm{m}$ [0.002 in] spring brass having a mass attached to the free end. A pair of small strain gauges is bonded to the faces of the spring. As the cell tilts, the weight of the mass bends the spring and strains the gauges. The output voltage is roughly proportional to the sine of the tilt angle, so that the tilt angle itself is ambiguous when the cell is tilted more than $90^{\circ}$ from vertical.

These cells are $47 \mathrm{~mm}$ in length and $16 \mathrm{~mm}$ in diameter. Each cell is made of acrylic and is filled with Dow Corning 200 fluid. This inert silicone fluid is nonconductive and non-corrosive, serves to dampen vibration of the masses and thwarts water infiltration (all these characteristics prove necessary). The damping fluid has a kinematic viscosity of $50 \mathrm{cSt} \quad\left(1 \mathrm{cSt}=1 \mathrm{~mm}^{2} \mathrm{~s}^{-1}\right.$; the centi-Stoke is the cgs unit often used to describe fluids in chemical supply-house catalogues). The pendulum weights are made of split lead shot. The cells are assembled into strings of three having a centre-to-centre spacing of $7.5 \mathrm{~cm}$. The cells are connected using $36 \mathrm{AWG}$ solid copper wires. The strain-bridge circuit is such that eight wires lead up to the surface from the upper cell, six wires connect the upper and middle cells and four wires connect the middle and lower cells. Because the protective heat-shrink sheath created problems in 1988, no sheath was placed over these sensor strings. Some permanent straining of the brass springs was observed to occur during the hammering process, but this shift in the calibration is easily corrected by using tilt recordings made before, during and after the insertion. In future, this problem could be avoided by using a higher-viscosity damping fluid and plastic leaf springs. Certain plastics have a much higher elastic limit than does brass and would accommodate greater strain.

The calibration process for leaf-spring tilt cells is identical to that for electrolytic tilt cells with the exception that the calibration range is extended to $90^{\circ}$ of tilt. The processing of in situ deformation data is somewhat different because the Newton-Raphson method does not yield a stable inversion. When the field data are analyzed, values $\theta$ and $\phi$ for the cell are computed from Equation (6) using a two-dimensional simplex algorithm (Press and others, 1986, p. 289) that minimizes the difference between predicted and observed output voltages. As with the electrolytic tilt cells, the error on tilt and azimuth for these sensors was estimated by using the calibration data as input to the inversion scheme. The sine of the tilt has a maximum error of \pm 0.005 , which translates into a $0.3^{\circ}$ error at $0^{\circ}$ of tilt, increasing to \pm 0.6 error at $60^{\circ}$ of tilt and to $\pm 5^{\circ}$ error at $90^{\circ}$ of tilt. The azimuth error is $\pm 4^{\circ}$ at $0^{\circ}$ of tilt,

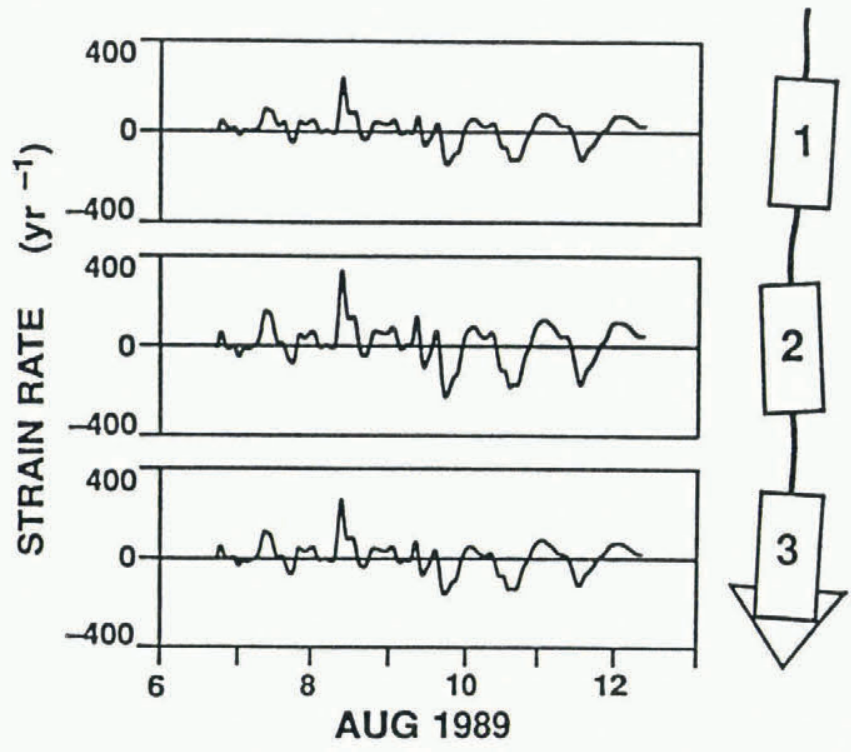

Fig. 7. Sample results from the 1989 leaf-spring tilt-sensor experiment. Tilt records for each of the three till cells have been differentiated to give strain rate parallel to ice flow. Strain rates normal to ice flow have been omitted for clarity, but are of comparable magnitude. 
decreasing to $\pm 1^{\circ}$ at $90^{\circ}$ of tilt. The error in strain rate is $0.003 \%$ at $0^{\circ}$ of tilt, increasing to $2 \%$ at $60^{\circ}$ of tilt.

Two sensor strings were hammered into the glacier bed during the summer of 1989. Unlike our experience in 1988, the initial tilt of these sensors was close to that of their respective insertion angles. Omitting the stiff protective sheath appears to have resulted in instruments that are flexible enough so as not to be forced from their insertion position. Figure 7 shows the down-flow strainrate data sensed by one of these leaf-spring tilt-cell strings. This string was inserted $20 \mathrm{~cm}$ into the undisturbed basal sediments and had an overall length of $27 \mathrm{~cm}$. After the insertion, the instrument cable was tied off with $1.5 \mathrm{~m}$ of slack. The signal from all three tilt cells indicates that they lay within actively deforming basal material. Because the insertion depth was not sufficient to place the uppermost cell within solid basal material and, because the cell did not have support from the cable, it must have been supported by the disturbed sediment layer. This sets the minimum thickness of the disturbed layer for this hole at about $10 \mathrm{~cm}$. We estimate that, in general, the thickness of the disturbed layer is $15-25 \mathrm{~cm}$.

These records were produced by performing a decomposition of the raw tilt and azimuth data, as is discussed above. Because the tilt measurements are made with respect to the vertical, we modify Equation (3) to include the basal slope of the glacier $\beta$ so that

$$
\dot{\epsilon}_{x z}=\frac{1}{2} \frac{\partial}{\partial t} \tan \left(\theta_{\mathrm{d}}-\beta\right) .
$$

The basal slope in the region surrounding the study area is $7^{\circ}$, as determined by drilling depths.

Cross-flow strain rates are not shown but are of comparable magnitude. This is a surprising result but one we accept because the alternative seems to be unacceptable; if the down-flow/cross-flow decomposition is constrained to prohibit cross-flow strain, then the implied motion of the cells requires back-and-forth rotation about their long axes by as much as $100^{\circ}$. There may be partitioning between cell rotation and cross-flow tilt but the effect on down-flow tilt is slight. Any fraction of cross-flow tilt that is assigned to cell rotation reduces cross-flow tilt by a similar fraction and down-flow tilt increases slightly to maintain the correct net tilt.

Strain rates were computed by applying a five-point running first-derivative filter to the strain record (Abramowitz and Stegun, 1965, p.914), followed by a Gaussian smoothing filter having a standard deviation of $50 \mathrm{~min}$.

The data have several interesting characteristics: (I) all three records are similar, indicating that each sensor was moving in concert with the others. This may indicate uniform deformation over the $20 \mathrm{~cm}$ length of the sensor string, or that the wires connecting the cells were exerting enough tension to keep the sensors aligned with one another. The former explanation is more plausible because we have data from other leaf-spring sensor strings that do not exhibit this synchronism. (2) For each of the three sensors, the average strain rate over the period of the experiment was of the order 10 year $^{-1}$, whereas the instantaneous strain rate was as large as 400 year $^{-1}$. (3) Negative and zero strain rates were observed. Though the average down-flow strain rate for each cell was positive, indicating net down-flow strain within the deforming layer, the periods of negative strain rate were frequent. (4) In the second half of the experiment, there was evidence of diurnal synchronization.

\section{POTENTIAL SOURCES OF ERROR}

Here we discuss sources of error that may arise from the insertion procedure and from sensor characteristics.

\section{Sensor-scale effects}

When making detailed measurements of deformation within an inhomogeneous material, a fundamental concern is choosing an appropriate scale of observation. If the scale of observation is too small (on the scale of individual clasts in the material), the concept of bulk viscosity becomes meaningless because there is no macroscopic, smooth velocity gradient along which shear stress may be transferred and viscosity defined. Undersized sensors would measure the random wanderings of individual clasts rather than the macroscopic properties of the deforming material. Conversely, if we observe the bed on too large a scale, the deforming layer appears as a single unit with no internal structure.

We expect the deforming layer beneath Trapridge Glacier to be decimeters thick (Boulton and Hindmarsh, 1987; Clarke, 1987), so we want to observe deformation on a scale of centimeters. Were the basal material beneath Trapridge Glacier homogeneous, our $5 \mathrm{~cm}$ long tilt sensors would make clear measurements of subglacial strain but this is not the case. A dry-volume fraction analysis of Trapridge Glacier basal material shows that $50 \%$ of the clasts are less than $0.25 \mathrm{~mm}$ in diameter and that $80 \%$ of the clasts are less than $2 \mathrm{~cm}$ in diameter (Clarke, 1987). Although these fractions increase once water is added to the system, the size of our tilt sensors is such that they behave as large clasts. There is no alternative but to accept this limitation because any technique for making local deformation measurements will be subject to the same conditions. Tilt cells placed near a clast of similar or larger size will be influenced by the movement of the clast, and Equations (3) and (4), which rely on the homogeneous nature of the basal material, may not be directly applicable.

\section{The ice-bed interface}

We cannot observe the insertion procedure directly and must rely on physical constraints and tactile information to infer what is happening at the bottom of the borehole. Our hot-water drill uses a $1.14 \mathrm{~mm}$ [0.045 in] diameter jet with a pressure drop of 7-14 MPa [1000-2000 psi] across the nozzle. We believe that hydraulic excavation by the drill loosens material to a depth of several decimeters below the ice bed interface. Evidence for this excavation includes the sediment-laden basal water samples that we obtain shortly after completing a borehole. When the percussion hammer is lowered to the bottom of a borehole, its dead weight exerts a pressure of about 
$1 \mathrm{MPa}$ on the tip (for comparison, the ice-overburden pressure beneath our study site is $0.64 \mathrm{MPa})$. This pressure pushes the hammer through the loosened material; the insertion process begins and is measured from the upper surface of the undisturbed bed material. Thus, the upper parts of the instrument may be below the ice-bed interface, even if the insertion depth into the undisturbed material is less than the length of the instrument. Typically, an insertion proceeds quickly for the first $5 \mathrm{~cm}$ and then slows down, suggesting that there is a gradation between the disturbed and undisturbed material. Evidence for the existence of the disturbed layer is found in the data and has been discussed above.

\section{Sensor attitude}

The diameter of the percussion hammer is $3.81 \mathrm{~cm}$ and, based on our experience with larger subglacial instruments, the diameter of the bottom of a borehole is just over $5 \mathrm{~cm}$. These radial dimensions, in combination with the $2 \mathrm{~m}$ length of the percussion hammer, ensure that the hammer fits snugly in the borehole and that the instrument is inserted into the subglacial sediment coaxially with the bottom of the hole. Each of the holes used for bed-deformation experiments was profiled using an inclinometer equipped with dual-axis tilt sensors and a compass. By determining the azimuth of the borehole as it intersects the ice-bed interface, we determine the initial azimuth of the bed-deformation instrument relative to the glacier-flow direction. The inclinometer is capable of determining the location of the bottom of a $70 \mathrm{~m}$ borehole to within $60 \mathrm{~cm}$. As they reach the bed, our boreholes commonly deviate from vertical by as much as $10-15^{\circ}$.

\section{Sediment intrusion into the borehole}

After the borehole is completed, several hours typically pass before the insertion procedure begins. This raises the concern that we may not insert our sensors into subglacial material, but rather into sediment that has squeezed into the borehole. We believe that this possibility can be ruled out because the observed shear-deformation rates exceed, by several orders of magnitude, the ice-deformation rates that would control sediment deformation within an icewalled hole. Moreover, using similar insertion techniques, we install other types of sensors into subglacial sediment and have unequivocal evidence that these sensors are implanted in bed material rather than extruded sediment. We discuss these two observations in turn.

The basal shear stress beneath Trapridge Glacier is $77 \mathrm{kPa}$ and the basal temperature of Trapridge Glacier in the study area is close to the pressure-melting point (Clarke and others, 1984, fig. 4, above site 11). Evaluating Glen's flow law for simple shear

$$
\dot{\epsilon}=A \tau^{n}
$$

at $0 \mathrm{C}$ gives a strain rate of $\dot{\epsilon}=0.076$ year $^{-1}$ when the shear stress $\tau=77 \mathrm{kPa}, A=5.3 \times 10^{-15} \mathrm{~s}^{-1} \mathrm{kPa}^{-3}$, and $n=3$ (Paterson, 1981, p. 39). Assuming Newtonian viscoelastic shear deformation of the form

$$
\eta=\frac{\tau}{2 \dot{\epsilon}}
$$

this strain rate represents a dynamic viscosity of $2 \times 10^{13} \mathrm{~Pa} \mathrm{~s}$. This ice-viscosity value is two orders of magnitude greater than published values of measured or predicted till viscosity (Boulton and Hindmarsh, 1987, fig. 7; Clarke, 1987). Given the low strain rate of the ice, we could not expect to measure strain rates exceeding 100 year $^{-1}$ within a borehole (see Fig. 7) if the straining of extruded material within a borehole were controlled by ice deformation.

In 1990, we ran a series of experiments using "dragspool" instruments. Our intent was to obtain some measure of the sliding rate beneath Trapridge Glacier. A drag spool consists of a multi-turn potentiometer connected to a spooled string. The drag spool is suspended within the ice close to the bed, and measures continuously the length of string payed out to an anchor in the bed.

The percussion hammer was used to insert three dragspool anchors in different boreholes to a depth within the undisturbed basal material similar to that of the 1989 deformation instruments. The data indicate that, on average, the anchor points moved away from their respective boreholes at a rate of about $4 \mathrm{~cm} \mathrm{~d}^{-1}$. This large relative velocity could not persist for many days if the anchor were placed in intruded material. Although these measurements were made at different sub-surface locations and during a different field season than the 1987-89 bed-deformation experiments, surface velocity in each season was about $10 \mathrm{~cm} \mathrm{~d}^{-1}$ and we have not made any changes to our drilling and insertion techniques during this time. Thus, it seems unlikely that basal conditions have undergone dramatic changes between the 1987-90 field seasons. We conclude that the anchors for our bed-deformation instruments are also below the icebed interface. If the upper parts of a deformation instrument were to extend above the ice bed interface, the data should show this as a rapid increase in tilt to $90^{\circ}$ as the tilt cells are drawn out of the borehole and in under the ice; we do not see this behaviour in any of our instruments.

\section{Connecting wires}

The two quantitative instrument designs require that thin wires connect the individual tilt sensors together and that a multi-conductor cable transmit the strain information to the surface.

The main instrument cable freezes to the side of the borehole, and could conceivably pull the entire sensor string out of the bed as the glacier slides forward. By letting slack cable down the hole after the instrument insertion is completed, we alleviate this problem. There is evidence from the 1988 results that this slack-cable technique is sufficient to prevent interference from the cable for several weeks.

The wires connecting the individual sensors are thin enough (36 AWG) so that they cannot prevent the sensor string from bending. Additional cladding, such as the heat-shrink sheath used in 1988, may stiffen the sensor string so that problems arise during the insertion procedure but, if the cladding is omitted, no problems arise. The connecting wires may also act under tension to align the sensors with each other. Any tension effect will 
become more acute as time passes. There is not much that can be done about this problem, other than using telemetry techniques that do not require wires. We can only be aware that the wires may cause interference.

\section{CONCLUDING REMARKS}

Our in situ measurements demonstrate that bed deformation is a more complex process than previous work has suggested (Boulton and Hindmarsh, 1987; manuscript in preparation by N.F. Humphrey, H.F. Engelhardt, M. Fahnstock and B. Kamb). Basal strain rate is observed to change sign, and to fluctuate wildly. If a deformation rate of $6 \mathrm{~cm} \mathrm{~d}^{-1}$ (surface velocity less sliding velocity as determined by the slidometers; internal ice deformation neglected) is associated with uniform shear deformation in a $1 \mathrm{~m}$ thick subglacial layer, then Equation (3) gives a basal strain rate of about 11 year $^{-1}$. The mean strain rates of about 10 year $^{-1}$ in Figure 7 are consistent with this estimate, but the instantaneous strain rate often exceeds the mean value by an order of magnitude and can be of opposite sign. The coherence of the three traces in Figure 7 suggests that this is not a consequence of local heterogeneity in the sediments. The erratic behaviour might be caused by rapid changes in the coupling between the glacier and the bed, or changes in the thickness of the deforming layer.

Our instruments measure only the velocity gradients within the deforming bed, and cannot determine the absolute velocity vectors. For this reason, we do not know whether negative strain rates indicate up-glacier motion in the bed or extrusive flow. The latter mechanism seems more likely, but may occur only within a several decimetre thick layer beneath the ice-bed interface. No physical constraints rule out extrusive flow within the bed. The data and their interpretation will be discussed more completely in subsequent papers.

\section{AGKNOWLEDGEMENTS}

The authors wish to acknowledge the contributions of B. B. Narod and M.L. Sowinski to the design and construction of these instruments. We thank the Canadian Northern Studies Trust of the Association of Canadian Universities for Northern Studies, the Natural Sciences and Engineering Research Council of Canada, and the Northern Science Training Program of the Department of Indian Affairs and Northern Development for their support.

\section{REFERENCES}

Abramowitz, M. and I. A. Stegun, eds. 1965. Handbook of mathematical functions with formulas, graphs, and mathematical tables. Cambridge, Cambridge University Press.

Boulton, G. S. and R. C.A. Hindmarsh. 1987. Sediment deformation beneath glaciers: rheology and geological consequences. f. Geophys. Res., 92 (B9), 9059-9082.

Clarke, G. K. C. 1987. Subglacial till: a physical framework for its properties and processes. 7. Geophys. Res., 92(B9), 9023-9036.

Clarke, G. K. C., S. G. Collins and D.E. Thompson. 1984. Flow, thermal structure, and subglacial conditions of a surge-type glacier. Can. 7. Earth Sci., 21(2), 232-240.

Paterson, W.S.B. 1981. The physics of glaciers. Second edition. Oxford, etc., Pergamon Press.

Press, W. H., B. P. Flannery, S. A. Teukolsky and W. T. Vetterling. 1986. Numerical recipes: the art of scientific computing. Cambridge, Cambridge University Press.

The accuracy of references in the text and in this list is the responsibility of the authors, to whom queries should be addressed. 